\title{
Abnormal permeability precedes the development of a gluten sensitive enteropathy in Irish setter dogs
}

\author{
E J Hall, R M Batt
}

\begin{abstract}
Intestinal permeability to ${ }^{51} \mathrm{Cr}$-EDTA was examined during the development of gluten sensitive enteropathy in dogs bred from affected Irish setters and reared on a normal wheat containing diet. Comparisons were made with litter mates reared on a gluten free diet and with a control group of age matched, clinically healthy Irish setters reared on the normal diet. Studies at 4, 6, 8, and 12 months of age were correlated with morphometric and biochemical examinations of peroral jejunal biopsy specimens. Permeability was increased at all ages in the group fed gluten free diet compared with control dogs, although there were no differences in villus height, intraepithelial lymphocyte density, and alkaline phosphatase activity. At four months, permeability in the normal diet group was greater than in controls, although comparable with that in the gluten free diet group. Permeability in the normal diet group increased further in conjunction with the development of partial villus atrophy and reduced alkaline phosphatase activity, and by 12 months permeability was significantly greater than in their gluten free diet litter mates and the control dogs. The findings suggest that an underlying permeability abnormality may be involved in the pathogenesis of gluten sensitive enteropathy in Irish setter dogs.
\end{abstract}

Increased intestinal permeability, shown in patients with untreated coeliac disease by many workers using ${ }^{51} \mathrm{Cr}-\mathrm{EDTA}^{1-6}$ or non-digestible sugars $^{7-12}$ as permeability probes, may be important as a marker of intestinal damage. In addition, it has been suggested that an underlying defect in permeability could play a primary role in the pathogenesis of coeliac disease. ${ }^{8}$ According to this hypothesis, a primary increase in mucosal permeability allows ingested gluten, or peptides derived from gluten digestion, to cross the intestinal epithelium, resulting in mucosal damage either by direct toxicity or by immune mediated mechanisms. ${ }^{13}$

Support for this hypothesis has been provided by evidence of increased intestinal permeability to ${ }^{51} \mathrm{Cr}$-EDTA not only in patients with untreated coeliac disease but also in patients successfully in remission on a gluten free diet. ${ }^{214}$ However, considerable overlap or no significant difference between the permeability to ${ }^{51} \mathrm{Cr}$-EDTA in treated coeliac patients and control subjects has been found by others. ${ }^{35} 1516$ Studies using alternative permeability probes have shown increased permeability in some patients investigated for intestinal disease but with apparently normal jejunal histology,"12 although careful morpho- metric analysis has detected subtle histological changes in these cases. ${ }^{917}$ No primary abnormality in coeliac disease has been shown using sugar permeability probes in patients successfully treated with a gluten free diet. ${ }^{18}{ }^{19}$ In one study, permeability decreased significantly after the introduction of a gluten free diet, although it remained greater than controls in five of 13 patients; however, this was correlated with the persistence of morphological abnormalities and apparent incomplete response to dietary therapy. ${ }^{20}$

Attempts to identify a primary permeability abnormality in treated coeliac disease patients may thus be frustrated by the difficulty of excluding inadvertent gluten ingestion and any potential long term effects of severe mucosal damage. An alternative approach to the inherent problems of investigating permeability in treated patients has been the examination of unaffected first degree relatives of patients with coeliac disease, but no increase in permeability to ${ }^{51} \mathrm{Cr}$-EDTA was shown despite increased intraepithelial lymphocyte populations in a percentage of the relatives. ${ }^{21}$

Examination of a suitable animal model might elucidate potential relations between enhanced intestinal permeability and mucosal damage by gluten. Recent studies have characterised a naturally occurring gluten sensitive enteropathy in Irish setter dogs. ${ }^{22}{ }^{23}$ Affected Irish setters fed a diet containing wheat show inappetance, poor weight gain or loss of weight, and chronic intermittent diarrhoea: these clinical signs improve after introduction of a cereal free diet. ${ }^{23}$ Jejunal changes include partial villus atrophy, accompanied by an increase in the relative number of intraepithelial lymphocytes, ${ }^{22-24}$ and a specific but secondary loss of brush border alkaline phosphatase on a normal diet containing wheat. ${ }^{25}$ These histological and biochemical abnormalities improve on feeding a wheat free diet and relapse on subsequent wheat challenge. ${ }^{23}$ Further studies have clearly shown that these abnormalities are related to the presence of gluten in the diet. ${ }^{26}$ Investigation of this naturally occurring animal model should therefore provide insight into the mechanism of damage to the intestinal mucosa by gluten.

The ${ }^{51} \mathrm{Cr}$-EDTA absorption test has been validated for the determination of intestinal permeability in the dog. ${ }^{27}$ In the present study, permeability to ${ }^{11} \mathrm{Cr}$-EDTA was examined in dogs bred from affected Irish setters and reared on a normal wheat containing diet, in litter mates reared on a cereal free diet, and in age matched normal Irish setters fed the wheat containing diet. Comparisons between these groups provide an opportunity to determine whether any changes in intestinal permeability are merely 
the result of mucosal damage by gluten or represent primary abnormalities which precede the development of the disease.

\section{Methods}

GROUPS OF ANIMALS

Thirteen Irish setter dogs, bred from Irish setters with documented gluten sensitive enteropathy, were studied. Details of these dogs have been reported previously. ${ }^{24}$ The progeny were allotted to two groups at 5-6 weeks of age, housed separately, and weaned. One group of six dogs was reared exclusively on a gluten free diet of rabbit and turkey meat (Mr Dog, Pedigree Petfoods). The other group of seven dogs was reared on a normal diet consisting of rabbit and turkey meat ( $\mathrm{Mr}$ Dog) with cereals containing wheat (Pedigree Chum Mixer, Pedigree Petfoods). Age matched controls were seven clinically healthy Irish setters, bred from unaffected parents, and fed the same diet of meat and cereal as the normal diet group. Investigations were performed at approximately $4,6,8$, and 12 months of age, as detailed previously. ${ }^{24}$

\section{MORPHOLOGIC STUDIES}

Jejunal biopsy specimens were obtained perorally from a site approximately $10 \mathrm{~cm}$ distal to the duodenal-jejunal flexure using a Quinton multiple suction biopsy capsule, ${ }^{23}$ after food had been withheld for approximately 18 hours. The tissues were fixed in $10 \%(\mathrm{w} / \mathrm{v})$ formalin, and after conventional processing, $5 \mu \mathrm{m}$ paraffin embedded sections were cut and stained with haematoxylin and eosin. The height of five sequential, well-orientated villi in coded sections were measured by use of a calibrated eyepiece graticule. Intraepithelial lymphocytes (numbers per 100 enterocytes) were counted in the midzone regions of these villi.

\section{BIOCHEMICAL STUDIES}

Portions of jejunal biopsy specimens were homogenised in sucrose medium $(0.3 \mathrm{~mol} / 1$ sucrose, $1 \mathrm{mmol} / 1 \mathrm{Na}_{2} \mathrm{EDTA}, 22 \mathrm{mmol} / \mathrm{l}$ ethanol, $\mathrm{pH} 7 \cdot 4$ ), and postnuclear supernatant and nuclear fractions were prepared. Jejunal organelle marker enzyme activities, including alkaline phosphatase, were assayed in the fractions. Subcellular fractionation was performed and the results for alkaline phosphatase and other organelle marker enzymes have been presented elsewhere. ${ }^{25}$ Protein was determined according to Schacterle and Pollack ${ }^{28}$ using bovine serum albumin (Armour Pharmaceutical Co) as standard.

\section{PERMEABILITY TO ${ }^{51}$ CR-EDTA}

Permeability to ${ }^{51} \mathrm{Cr}$-EDTA was assessed in each dog one to two weeks before jejunal biopsy, using the procedure reported previously. ${ }^{27}$ The test solution contained $50 \mu \mathrm{Ci}(1.35 \mathrm{MBq})$ of ${ }^{51} \mathrm{Cr}$-EDTA (specific activity 1 to $2 \mathrm{mCi} / \mathrm{mgCr}$, Amersham International) in $50 \mathrm{ml}$ of distilled water; a $5 \mathrm{ml}$ aliquot was retained as a counting standard. After food had been withheld from the dogs for 15 hours, $45 \mathrm{ml}$ of the ${ }^{51} \mathrm{Cr}$-EDTA solution was given intragastrically by a stomach tube, which was then flushed with $55 \mathrm{ml}$ of water. Each dog was then placed in a metabolism cage for 24 hours; water was available ad libitum and food was given after six hours. At the end of 24 hours, the bladder was catheterised and the urine was pooled with any urine collected in the cage, and the total volume recorded. No dog passed faeces during the 24 hour period in the metabolism cage.

The percentage urinary recovery of the administered dose of ${ }^{51} \mathrm{Cr}$-EDTA was calculated by counting the radioactivity in five $2.5 \mathrm{ml}$ aliquots of urine samples and 1:100 dilutions of the standards in a LKB-Wallac 1270 Rackgamma counter. Each sample was counted for five minutes; the coefficient of variation was between 1.2 and $6.0 \%$ depending on the level of radioactivity. Sensitivity was $0.03 \%$ of the administered dose per litre of urine.

\section{STATISTICS}

After testing for homogeneity of variance by Levene's test, comparisons of results from the three groups at each age were performed by analysis of variance and Newman-Keuls test. Differences with a $p$ value $<0.05$ were considered to be significant.

\section{Results}

Offspring of affected dogs fed the normal diet containing wheat showed clinical signs of poor appetite and chronic intermittent diarrhoea typical of gluten sensitive enteropathy ${ }^{22}$ whereas littermates fed a gluten free diet and controls were clinically healthy.

\section{MORPHOLOGIC STUDIES}

Results of the morphometric analysis of the sections of biopsy specimens have been presented

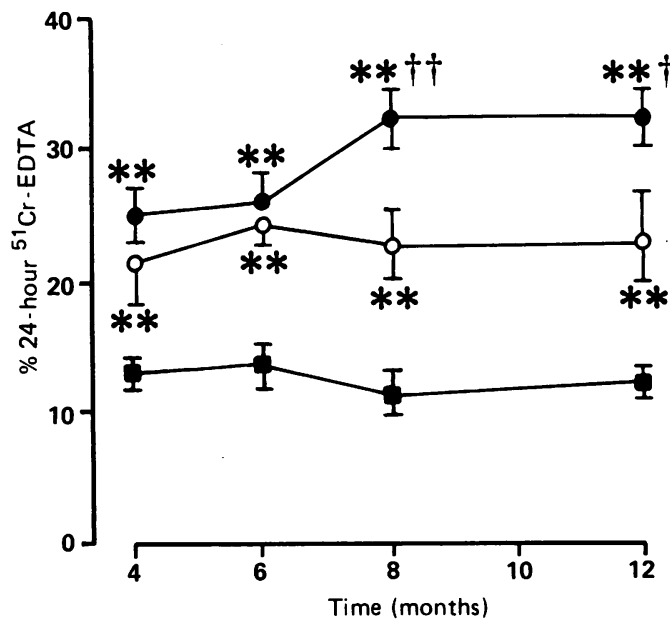

Percentage 24 hour urinary excretion of ingested "Cr-EDTA from offspring of affected Irish setters and from control setters $(C$; closed square) after intragastric administration of $50 \mu C i$ of ${ }^{\prime \prime} C r-E D T A$. Offspring of affected dogs were fed either a normal wheat containing diet (ND; closed circle) and eventually showed intestinal damage, or were fed a gluten free diet (GFD; open circle) and showed no intestinal damage. Data are expressed as mean (SEM). Significance of statistical comparisons: ${ }^{\star}=p<0.01 \mathrm{v} C ; \dagger=p<0.05 ; \dagger+p<0.01$ vGFD. 
Examination of jejunal biopsy specimens from affected dogs on a normal diet $(N D)$ or a gluten free diet $(G F D)$, and from control dogs $(C)$. Values are mean (SEM)

\begin{tabular}{|c|c|c|c|c|c|}
\hline & \multirow[t]{2}{*}{ Group } & \multicolumn{4}{|l|}{ Age } \\
\hline & & $4 \mathrm{mths}$ & 6 mths & $8 \mathrm{mths}$ & $12 \mathrm{mths}$ \\
\hline $\begin{array}{l}\text { Villus height } \\
(\mu \mathrm{m}) \\
\text { Intraepithelial } \\
\text { Lymphocytes } \\
\text { (Per 100 enterocytes) } \\
\text { Alkaline phosphatase } \\
\text { (mU/mg protein) }\end{array}$ & $\begin{array}{l}\text { C } \\
\text { GFD } \\
\text { ND } \\
\text { C } \\
\text { GFD } \\
\text { ND } \\
\text { C } \\
\text { GFD } \\
\text { ND }\end{array}$ & $\begin{array}{l}928(41) \\
995(16) \\
890(33) \\
8 \cdot 8(1 \cdot 0) \\
9 \cdot 4(0 \cdot 8) \\
19 \cdot 2(1 \cdot 8)^{\star} \ddagger \\
177(12) \\
174(44) \\
148(24)\end{array}$ & $\begin{array}{c}1034(16) \\
997(36) \\
856(28)^{\star} \ddagger \\
9 \cdot 6(0 \cdot 8) \\
8 \cdot 2(1 \cdot 5) \\
16 \cdot 7(1 \cdot 2)^{\star} \ddagger \\
193(20) \\
171(12) \\
126(15)^{\star}\end{array}$ & $\begin{array}{c}967(35) \\
1032(36) \\
811(39)^{\star} \ddagger \\
9 \cdot 8(1 \cdot 0) \\
7 \cdot 6(1 \cdot 2) \\
18 \cdot 5(1 \cdot 0)^{\star} \ddagger \\
253(21) \\
240(26) \\
181(18)^{\star}\end{array}$ & $\begin{array}{l}1064(34) \\
996(29) \\
739(19)^{\star} \ddagger \\
10 \cdot 6(0 \cdot 5) \\
9 \cdot 4(0 \cdot 8) \\
19 \cdot 6(0 \cdot 5)^{\star} \ddagger \\
221(17) \\
188(18) \\
90(11)^{\star} \ddagger\end{array}$ \\
\hline
\end{tabular}

Significance of statistical comparisons: ${ }^{\star}=\mathrm{p}<0.01 v \mathrm{C} ; \dagger=\mathrm{p}<0.05 ; \ddagger=\mathrm{p}<0.01 v$ GFD.

elsewhere ${ }^{24}$ and are summarised in the Table. Villus height in the normal diet group was unaffected at 4 months but was significantly decreased from 6 months onward, compared with both the controls and the progeny of affected dogs fed a gluten free diet. An increase in the number of intraepithelial lymphocytes was a consistent feature in the normal diet group at all ages, whereas there were no differences comparing progeny of affected dogs reared on a gluten free diet with controls.

\section{BIOCHEMICAL STUDIES}

Full results of the biochemical analyses of the biopsy specimens have been presented elsewhere $^{25}$; results of alkaline phosphatase activity are shown in the Table. In the affected progeny fed a normal diet, specific activities of alkaline phosphatase were unaffected at 4 months, but were significantly lower than controls by 6 months, and had fallen noticeably by 12 months to values significantly different not only from controls but also from litter mates fed a gluten free diet.

\section{PERMEABILITY TO ${ }^{51} \mathrm{CR}$-EDTA}

The percentage 24 hour urinary excretion of ${ }^{51} \mathrm{Cr}$-EDTA in both normal and gluten free diet groups of affected progeny was significantly greater than in controls at all times (Figure). At 4 months excretion in the normal diet group was comparable with the gluten free diet group, but increased by 8 months to become significantly greater compared not only with the controls but also with their litter mates on a gluten free diet.

\section{Discussion}

It has been shown that intestinal permeability to ${ }^{51} \mathrm{Cr}$-EDTA is increased in approximately $80 \%$ of coeliac disease patients successfully treated with a gluten free diet. ${ }^{12}$ Such a persistent increase in intestinal permeability in treated patients lends support to the hypothesis that deranged permeability could be a primary defect involved in the aetiopathogenesis of the condition. ${ }^{813}$ Persistent ultrastructural lesions have been described in biopsy specimens from children with coeliac disease in remission on a gluten free diet, despite normal dissecting and light microscopy findings, ${ }^{29}$ and these might be relevant to a permeability defect.

Despite the finding of apparently normal jejunal mucosa in treated coeliac patients with increased permeability to ${ }^{51} \mathrm{Cr}$-EDTA, however, suspicion may remain as to the complete absence of gluten from the diet,' and the patients' compliance to a strictly gluten free diet with abstinence from substances known to increase permeability to ${ }^{51} \mathrm{Cr}$-EDTA, such as alcohol and non-steroidal anti-inflammatory drugs. ${ }^{30}$ Other studies of treated coeliac disease patients, using ${ }^{51} \mathrm{Cr}$-EDTA ${ }^{351516}$ or other probes ${ }^{18-20}$ to measure intestinal permeability, have not provided any clear evidence of a primary permeability abnormality. These conflicting results may be explained by the different sensitivities of the tests and the failure to include appropriate controls, ${ }^{30}$ variations in control values between different populations, ${ }^{31}$ and the different osmolarities of the test solutions used. ${ }^{32}$

Identification of a primary permeability abnormality in patients with coeliac disease may be impossible because of the difficulties of interpretation arising from the severe disruption of mucosal integrity that occurs, causing nonspecific secondary increase in permeability. Examination of treated coeliac disease patients is complicated by the difficulties of complete gluten exclusion and the potential long term effects on mucosa after apparent recovery. Thus, measurement of intestinal permeability in a suitable animal model of gluten sensitivity would provide an opportunity to determine whether a primary permeability defect may be relevant to the mechanism of gluten toxicity. The study of Irish setter dogs with naturally occurring gluten sensitive enteropathy permits examination of whether a primary permeability abnormality could be involved in the mechanism of mucosal damage by gluten.

Sequential examination of biopsy specimens in the present study showed the characteristic changes - partial villus atrophy, intraepithelial lymphocyte infiltration, and reduced alkaline phosphatase activity - of gluten sensitive enteropathy ${ }^{22-25}$ in affected dogs reared on a normal wheat containing diet. The reduction in villus height and alkaline phosphatase activity in affected dogs in response to dietary wheat was evident by 6 months of age and was progressive, with noticeable reductions by 12 months of age. As expected, affected progeny that were fed a diet containing wheat had morphological and biochemical evidence of intestinal damage, and indeed had the greatest permeability to ${ }^{51} \mathrm{Cr}$ EDTA. Permeability was also increased at 4 months of age, however, compared with controls, before the development of mucosal damage.

In the absence of dietary wheat, villus height, intraepithelial lymphocyte density, and alkaline phosphatase activity in progeny of affected dogs were no different from the control dogs. Yet significantly, these progeny on a gluten free diet also exhibited increased permeability when compared with controls, despite the absence of morphological or biochemical evidence of intestinal damage; these dogs did excrete less ${ }^{51} \mathrm{Cr}$ EDTA than the normal diet group, but this would be expected in the absence of gross mucosal damage.

The pathway across the mucosa taken by ${ }^{51} \mathrm{Cr}$ - 
EDTA is believed to be paracellular, and permeation to ${ }^{51} \mathrm{Cr}$-EDTA in experimental models has been shown to correlate with permeation to oligopeptides $^{33}$ and macromolecules, ${ }^{34}$ and the formation of circulating immune complexes in vivo. ${ }^{35}$ The mucosa in coeliac disease has been shown to have increased permeability to dietary antigens, ${ }^{36}$ and the size of ${ }^{51} \mathrm{Cr}$-EDTA (mol wt 340 ) is within an order of magnitude of the smallest gliadin peptides (mol wt 500-1000), produced by enzymatic digestion, that have been shown to be toxic in coeliac disease..$^{37}{ }^{38}$ Access of gluten or gluten derived peptides across the intestinal epithelium could initiate a pathological process, either by direct toxicity or by activating immune cascade mechanisms.

The increase in intraepithelial lymphocyte density seen in the normal diet group was an early response to the presence of gluten in the diet, and could represent an immune response to entry of gluten or gluten derived peptides across the epithelial barrier. It remains to be determined whether such an intraepithelial lymphocyte infiltration is merely a secondary response to an abnormally permeable mucosa, or represents a primary immunological abnormality. The further increase in permeability, presumably secondary to the intestinal damage present in the normal diet group fed wheat, would perhaps permit greater access of potential antigens into the lamina propria thereby exacerbating the damage.

In mature control Irish setters the 24 hour urinary excretion of ${ }^{51} \mathrm{Cr}$-EDTA after peroral administration is approximately $10 \%$, and much greater than that reported for $\operatorname{man}^{30}$; the significance of this is discussed elsewhere. ${ }^{27}$ Despite this high natural intestinal permeability in canines compared with other species, increased permeability apparently exists in affected Irish setters compared with control Irish setters, although it may be speculated that the apparent increase in permeability in the gluten free diet group, despite the lack of evidence of intestinal damage, was caused by extraneous factors.

Mucosal integrity can be damaged by EDTA ${ }^{39}$ and its presence in the test solution, to stabilise ${ }^{51} \mathrm{Cr}$-EDTA, could theoretically damage the mucosal barrier of affected progeny more than controls. The concentration of EDTA reported to produce changes in permeability, however, is one thousand times greater than that of the test solution. Another possible factor is the diet of the gluten free diet group, which is an all meat product and could increase intestinal transit time. ${ }^{40}$ However, the total transit time in all these dogs was greater than 24 hours, and so an effect on the permeation of ${ }^{51} \mathrm{Cr}$-EDTA would only be seen if the permeability of small intestinal and colonic mucosa were different. Furthermore, dogs in the normal diet group were fed the same diet as the controls, and yet before they developed intestinal damage they had increased permeability compared with the controls.

The diet fed to the gluten free diet dogs was strictly gluten free, but could contain some other component to which these dogs are also sensitive. Carrageenan, for example, is present in some proprietary dog foods and has been shown to cause an increased intestinal perme- ability in rats without producing any histological abnormalities. ${ }^{41}$ Thus, the permeability abnormality may not be a primary defect but secondary to the presence of another dietary component that increases permeability and thereby permits access of gluten to the mucosa. Elemental diets have been shown to reduce intestinal permeability in Crohn's disease, ${ }^{42}$ where permeability to macromolecules may be involved in the pathogenesis of the condition. ${ }^{13} \mathrm{It}$ would be interesting to measure the intestinal permeability of these dogs while they are maintained on an elemental diet in order to eliminate the effects of any potential dietary sensitivity.

In conclusion, increased permeability to ${ }^{51} \mathrm{Cr}$ EDTA was found in progeny of affected Irish setters fed a gluten free diet, although there was no morphological or biochemical evidence of intestinal damage. Increased permeability was also found preceding the development of gluten sensitive enteropathy in affected dogs reared on a diet containing wheat. These findings suggest that an underlying permeability abnormality may be important in the pathogenesis of gluten sensitive enteropathy in Irish setters. Further increases in permeability reflected the development of overt intestinal damage secondary to the ingestion of gluten. Any correlation between increased ${ }^{51} \mathrm{Cr}$-EDTA permeation and permeability to gluten or gluten derived peptides in affected Irish setters remains to be determined.

Supported by the Wellcome Trust. Presented in abstract form at the British Society of Gastroenterology Meeting, Warwick, March 1990.

1 Bjarnason I, Peters TJ, Veall N. A persistent defect in intestinal permeability in coeliac disease demonstrated by ${ }^{51} \mathrm{Cr}$-labelled EDTA absorption test. Lancet 1983; i: 323-5.

2 Bjarnason I, Marsh MN, Price A, et al. Intestinal permeability in patients with coeliac disease and dermatitis herpetiformis. Gut 1985; 26: 1214-9.

3 Behrens RH, Szaz KF, Northrop C, Elia M, Neale G. Radionucleide tests for the assessment of intestinal permeability. Eur f Clin Invest 1987; 17: 100-5.

4 Martines D, Morris AI, Gilmore IT, et al. Comparison between the cellobiose/mannitol and ${ }^{\text {si }} \mathrm{Cr}$-labelled ethylenediaminetetra-acetate absorption tests in the detection of diaminetetra-acetate absorption tests in

5 Fotherby KJ, Wraight EP, Neale G. ${ }^{11} \mathrm{Cr}$-EDTA/ ${ }^{14} \mathrm{C}-$ Mannito intestinal permeability test. Clinical use in screening for intestinal permeability test. Clinical use in screenin
coeliac disease. Scand $\mathcal{F}$ Gastroenterol 1988; 23: 171-7.

6 Turck D, Ythier H, Maquet E, et al. Intestinal permeability to ['Cr]EDTA in children with Crohn's disease and celiac disease. F Pediatr Gastroenterol Nutr 1987; 6: 535-7.

7 Menzies IS. Absorption of intact oligosaccharide in health and disease. Biochem Soc Trans 1974; 2: 1042-7.

8 Menzies IS, Laker MF, Pounder R, et al. Abnormal intestina permeability to sugars in villous atrophy. Lancet 1979; ii: 1107-9.

9 Strobel S, Brydon WG, Ferguson A. Cellobiose/mannito sugar permeability test complements biopsy histopathology in clinical investigation of the jejunum. Gut 1984; 25 . in clinical

10 Stenhammar L, Strömberg S. Intestinal permeability to lactulose/L-rhamnose in children with celiac disease and other gastrointestinal disorders. F Pediatr Gastroenterol Nutr 1988; 7: 304-5.

11 Juby LD, Rothwell J, Axon ATR. Cellobiose/mannitol sugar test: a sensitive tubeless test for coeliac disease: results on 1010 unselected patients. Gut 1989; 30: 476-80

12 Juby LD, Rothwell J, Axon ATR. Lactulose/mannitol test: an ideal screen for celiac disease. Gastroenterology 1989; 96: 79-85.

13 Bjarnason I, Peters TJ. Helping the mucosa make sense of macromolecules. Gut 1987; 28: 1057-61.

14 Dawson DJ, Lobley RW, Burrows PC, Notman JA, Mahon $M$, Holmes $R$. Changes in jejunal permeability and passive and Crohn's disease. Clin Sci 1988; 74: 427-31.

and Crohn's disease. Clin Sci 1988; 74: 427-31. DG, Feighery CF. 'SCr-EDTA test for coeliac disease. DG, Feighery CF.

16 Peled Y, Watz C, Gilat T. Measurements of intestinal permeability using 'SiCr-EDTA. Am f Gastroenterol 1985; 80: ability

17 Juby LD, Dixon MF, Axon ATR. Abnormal intestinal 
permeability and jejunal morphometry. $\mathcal{F}$ Clin Pathol 1987; 40: 714-8.

18 Hamilton I, Cobden I, Rothwell J, Axon ATR. Intestinal permeability in coeliac disease: the response to gluten withdrawal and single-dose gluten challenge. Gut 1982; 23: 202-10.

19 Stenhammar L, Fälth-Magnusson K, Jansson G, Magnusson $\mathrm{K}-\mathrm{E}$, Sundqvist T. Intestinal permeability to inert sugars and different polyethyleneglycols in children with celiac disease. $\mathcal{F}$ Pediatr Gastroenterol Nutr 1989; 8: 281-9.

20 Ukabam SO, Cooper BT. Small intestinal permeability as an indicator of jejunal mucosal recovery in patients with celiac sprue on a gluten-free diet. $\mathcal{F}$ Clin Gastroenterol 1985; 7: 232-6.

21 Marsh MN, Bjarnason I, Shaw J, Ellis A, Baker R, Peters TJ. Studies of intestinal lymphoid tissue. XIV-HLA status, mucosal morphology, permeability and epithelial lymphomucosal morphology, permeability and epithelial lymphocyte populations in first degree re

22 Batt RM, Carter MW, McLean L. Morphological and biochemical studies of a naturally occurring enteropathy in the Irish setter dog: a comparison with coeliac disease in man. Res Vet Sci 1984; 37: 339-46.

23 Batt RM, McLean L, Carter MW. Sequential morphologic and biochemical studies of naturally occurring wheatsensitive enteropathy in Irish setter dogs. Dig Dis Sci 1987; 32: 184-94

24 Hall EJ, Batt RM. Development of wheat-sensitive enteropathy in Irish setters: morphologic changes. Am $\mathcal{F}$ Vet Res pathy in 1rish se.

25 Hall EJ, Batt RM. Development of wheat-sensitive enteropathy in Irish setters: biochemical changes. Am $\mathcal{J}$ Vet Res pathy in Irish se.

26 Hall EJ, Batt RM. Challenge studies demonstrate gluten sensitivity of a naturally occurring enteropathy in Irish sette dogs [Abstract]. Gastroenterology 1988; 94: A167.

27 Hall EJ, Batt RM, Brown A. Assessment of canine intestinal permeability, using ${ }^{\text {S1 }}$ chromium-labeled ethylenediaminetetra-acetate. Am 7 Vet Res 1989; 50: 2069-74.

28 Schacterle GR, Pollack RL. A simplified method for the quantitative assay of small amounts of protein in biologic material. Anal Biochem 1973; 51: 654-5.

29 Stenling R, Fredrikzon B, Engberg S, Falkmer S. Surface ultrastructure of the small intestinal mucosa in children with coeliac disease. I. Untreated disease and effects of long-term
gluten elimination and challenge. Ultrastruct Pathol 1984; 6: gluten el.
30 Bjarnason I, Peters TJ, Veall N. ${ }^{\text {II }} \mathrm{Cr}$-EDTA test for intestinal permeability. Lancet 1984; ii: 523 .

31 Bourke S, Murphy B, Stafford F, Maher K, O'Morain C. Population differences in intestinal permeability to chromium EDTA. Ir F Med Sci 1988; 157: 287-9.

32 Smethurst P, Menzies IS, Levi AJ, Bjarnason I. Intestinal permeability: osmolarity revisited [Abstract]. Gut 1988; 29: A1479-80.

33 Ferry DM, Butt TJ, Broom MF, Hunter J, Chadwick VS Bacterial chemotactic oligopeptides and the intestinal mucosal barrier. Gastroenterology 1989; 97: 61-7.

34 Ramage JK, Stanisz A, Scicchitano R, Hunt RH, Perdue MH. Effect of immunologic reactions on rat intestinal epithelium. Correlations of increased intestinal permeability to chromium 51-labeled ethlenediaminetetracetic acid and ovalbumin during acute inflammation and anaphylaxis. Gastroenterology 1988; 94: 1368-75.

35 Davin J-C, Forget P, Mahieu PR. Increased intestinal permeability to (51Cr) EDTA is correlated with $\operatorname{IgA}$ immune complex-plasma levels in children with IgA-associated nephropathies. Acta Paediatr Scand 1988; 77: 118-24.

36 Husby S, Foged N, Høst A, Svehag S-E. Passage of dietary antigens into the blood of children with coeliac disease. Quantification and size distribution of absorbed antigens. Gut 1987; 28: 1062-72.

37 Bronstein HD, Haeffner LJ, Kowlessar OD. Enzymatic digestion of gliadin; the effect of the resultant peptides in adult celiac disease. Clin Chim Acta 1966; 14: 141-55.

38 Offord RE, Anand BS, Piris J, Truelove SC. Further subfractionation of digests of gluten. In: McNicholl B, McCarthy tionation of digests of gluten. In: McNicholl B, McCarthy CF, Fottrell PF, eds. Perspective

39 Ahrens FA, Aronson AL. A comparative study of the toxic effects of calcium and chromium chelates of ethylenediaminetetraacetate in the dog. Toxicol Appl Pharmacol 1970; 18: 10-25.

40 Cherbut Ch, Meirieu O, Ruckebush Y. Effect of diet on intestinal xylose absorption in dogs. Dig Dis $S c i$ 1986; 31: 385-91.

41 Delahunty T, Recher L, Hollander D. Intestinal permeability changes in rodents: a possible mechanism for degraded carrageenan-induced colitis. Food Chem Toxicol 1987; 86A: 565-7.

42 Sanderson IR, Boulton P, Menzies I, Walker-Smith JA. Improvement of abnormal lactulose/rhamnose permeability Improvement of abnormal lactulose/rhamnose permeability diet. Gut 1987; 28: 1073-6. 